\title{
Performance analysis routing protocol between RIPv2 and EIGRP with termination test on full mesh topology
}

\author{
D. R. Prehanto ${ }^{1}$, A. D. Indriyanti ${ }^{2}$, G. S. Permadi ${ }^{3}$ \\ 1,2 Department of Information System, Faculty of Engineering, Universitas Negeri Surabaya, Indonesia \\ ${ }^{3}$ Department of Information Management, Faculty of Information Technology, Universitas Hasyim Asy'ari, Indonesia
}

\begin{tabular}{|c|c|}
\hline Article Info & ABSTRACT \\
\hline & \multirow{9}{*}{$\begin{array}{l}\text { Data access on a company is a very important part of an institution or a } \\
\text { college. Especially in the present time, the internet has become an important } \\
\text { thing in human life. With the existence of certain means there is a problem } \\
\text { that will arise, needed solution or way out on a network that can be called } \\
\text { protocol. Because an institution needs to choose network methods properly } \\
\text { and safely. This study focuses on addressing the path/route of data packets to } \\
\text { be sent will be governed by this routing protocol in the form of table routing. } \\
\text { Routing used adip routing information protocol version } 2 \text { (RIPv2) with } \\
\text { enhanced interior gateway routing protocol (EIGRP) which will be compared } \\
\text { on both routing protocol which is better against predetermined situation } \\
\text { previous. The result of the research using cisco packet tracer } 7.10 \text { software } \\
\text { shows that EIGRP routing run on two topologies has faster convergence time } \\
\text { speed with an average time of } 0.01-0.02 \text { seconds as well as the change of its } \\
\text { routing table at once. Unlike RIPv } 2 \text { routing that takes longer than EIGRP } \\
\text { routing is with the time range from } 0.01 \text { to } 0.19 \text {. }\end{array}$} \\
\hline Received Mar 16, 2020 & \\
\hline Revised May 26, 2021 & \\
\hline Accepted Jun 14, 2021 & \\
\hline Keywords: & \\
\hline EIGRP & \\
\hline Performance & \\
\hline RIPv2 & \\
\hline Routing & \\
\hline
\end{tabular}

This is an open access article under the CC BY-SA license.

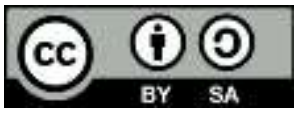

Corresponding Author:

D. R. Prehanto

Department Information System, Faculty of Engineering

Universitas Negeri Surabaya

Building E1, Ketintang St., Surabaya City, East Java 60231, Indonesia

Email: dedyrahman@unesa.ac.id

\section{INTRODUCTION}

Computer network technology in an institution or college is a very important part [1]. With the means there must be a problem that will emerge, needed solutions or solutions on a network that can be called a protocol, which regulates traffic on a network. Likewise with the use of the internet certainly requires a protocol that regulates the course of packets on the internet network [2]. There are various kinds of algorithms in managing the routing process, these rules are known as routing protocols [3].

This study aims to determine the best topology in each routing protocol. Because each routing protocol has different properties, research is done using enhanced interior gateway routing protocol (EIGRP) and routing information protocol version 2 (RIPv2) routing protocols that are tested through simulation using cisco packet tracer 7.1 software [4] and 10 routers will be configured using full mesh and half mesh topology with serial cable media to connect between routers and Straight-Through type Fast Ethernet cable to connect the router to the switch and connect the switch to the personal computer (PC) [5].

Tests focused on, among others, the resulting routing table list, the stability of the network through the ping command, and examining the path that is passed by a data packet using trace routes [6]. Then a comparative analysis is performed based on the results of several aspects of the test. So, conclusions will be obtained that show a superior routing protocol [7]. This research tries to compare the routing protocol, RIPv2 
with open shortest path first (OSPF) which will be sought in both protocols which are better in a predetermined situation [8].

\section{RESEARCH METHOD}

\subsection{Routing}

Routing is the process of choosing the path that must be passed by package [9]. Good path depends on network load, datagram length, type of service requested and traffic patterns. In general, the routing scheme only consider the shortest path. There are 2 form of routing, namely, direct routing and indirect routing [10].

\subsection{EIGRP}

Referring to the CCNA lab guide nixtrain, EIGRP is also called as a routing protocoldistance vector [11], sometimes also called advanced distance vector or hybrid routing protocol [12]. EIGRP maintains three tables [13].

- Neighbor table: a table that stores information about the router others that run EIGRP routing and connect directly with the router itself, because EIGRP only shares information routing with a router that only exists in this table [14].

- Topology table: a table that stores all information about the path learned from neighbors. In this table are stored all destinations and paths shared by neighbor routers.

- Routing table; the table that only stores the fastest destinations for get to every destination.

\subsection{RIPv2}

Routing information protocol (RIP) is a term that often comes out in the world of distance vector routing protocol internet networks whose routing metrics use hops. The hold time for the stop is 180 seconds. The rules for the number of jumps allowed from source path to destination path. The maximum number of hops allowed for RIP is 15. This hop limit is intended to limit the size of the network that can perform RIP support [15]. RIP implements split horizon, route poisoning and holddown mechanisms [16].

In most of today's network environments, EIGRP, OSPF, or IS-IS is more of a choice than RIP for routing as diffuse time and scalability [17]. However, it is easy to configure, because RIP is not need parameters on a router in another protocol oppo. This is assigning a statutory protected port number 520 . There are 3 versions from routing information protocol: RIPv1, RIPv2, and RIPng [18].

Departing from the shortcomings in the previous RIP, it became the basis for the development of RIPv2 in 1993 and later developed in 1998. RIPv2 supports classless inter-domain routing (CIDR) because it has the ability to carry subnet information. For compatibility, the hop limit of 15 is fixed. One of the perks of RIPv2 to fully operational with initial specifications if all protocols must be Zero fields in RIPv1 messages are specified correctly [19]. Also, activate feature compatibility enables smooth interoperability adjustments [20]. This 224.0.0.9 address is at the address IP version 4 class D. RIPv2 is the STD-56 Internet Standard [21].

\subsection{Full mesh topology}

Physical topology is a physical description of the relationships between network components. Refer to the cisco CCNA and computer networks book. Mesh topology describes each computer connected point-to-point. This means that each computer is directly connected to all computers on the network [22]. Mesh topology is divided into 2 types, namely fully connected mesh topology and partially connected mesh topology [23]. For example, if there are 5 device in the network, one device will be connected to 4 other device, this topology is also called a full mesh topology [24], as shown in Figure 1.

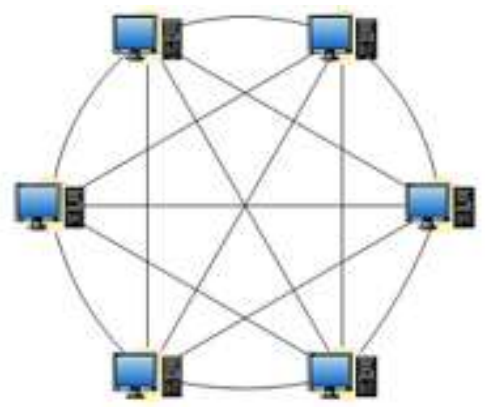

Figure 1. Full mesh topology 


\section{RESULTS AND ANALYSIS}

\subsection{Scenario anaysis}

After all the settings and configurations in the system design have been The next stage is completed, namely testing of the system that has been made. What will be tested in the system will be explained in Figure 2. From Figure 2, testing the scenarios that can be explained are:

- In this study using cisco packet tracer version 7.1 and simulation configuration using full mesh topology with EIGRP and RIPv2 routing protocols as Figure 3.

- The underlying arrangement made a full lattice geography recreation utilizing 10 switches, every switch is associated straightforwardly to different switches that are neighbors to the switch. Also, every one of these switches will have one customer, as ashown in Table 1. The customer will be utilized for information transmission, for example, Figure 4. Next the IP customer on the other PC is likewise decided, appeared in the Figure 5.

- The next experiment was to test network connectivity with the ping command on each network. After that the process of sending data packets from one network to another network, then do traceroute such as Figure 6.

- Subsequent experiments will be carried out to determine the speed of data transmission based on the time taken by the routing in the condition of the path will be broken one of them will then be calculated time for the path to find how much time is needed such as Figure 7.

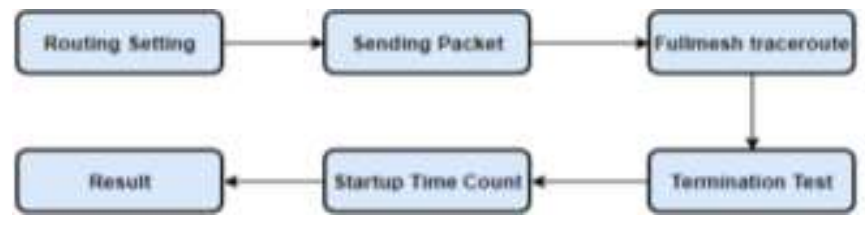

Figure 2. Testing the scenarios

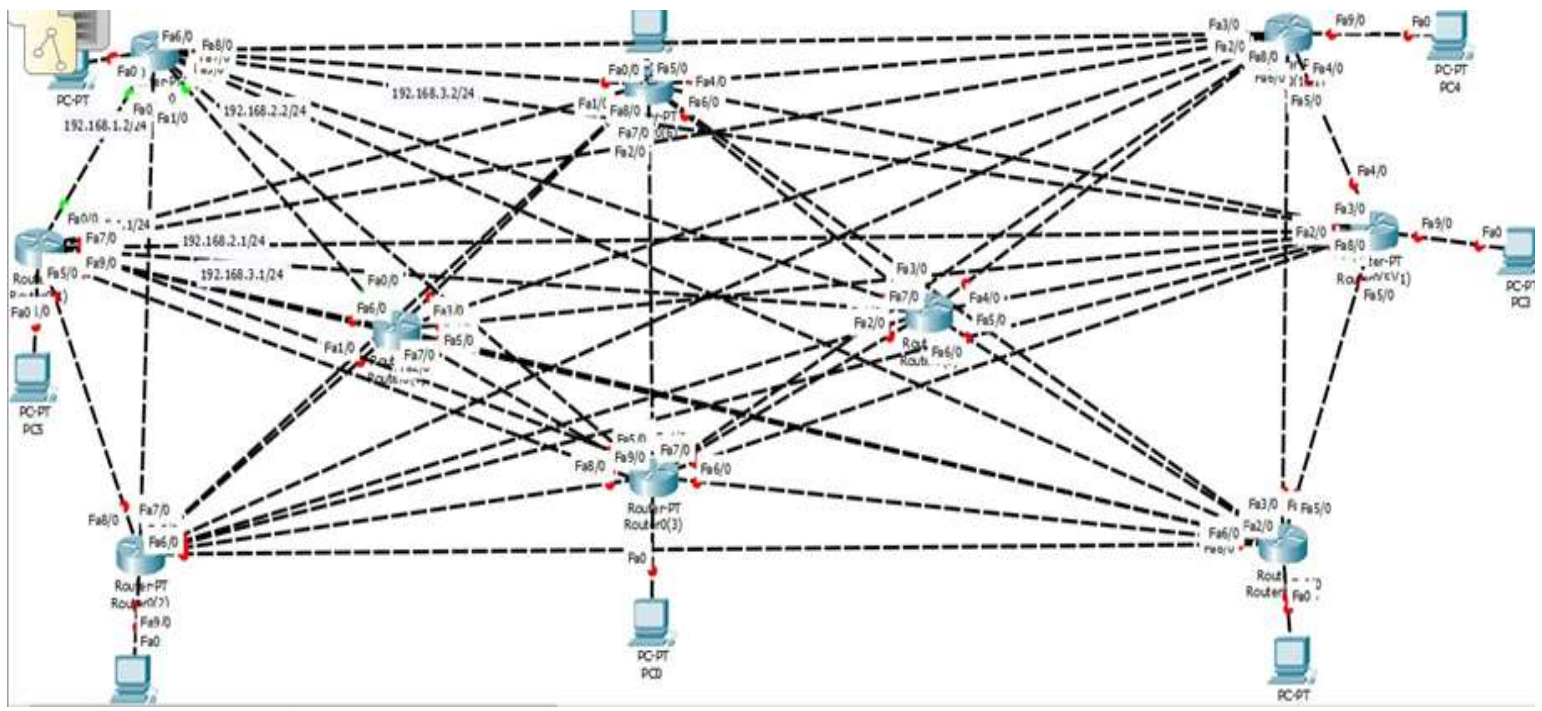

Figure 3. Full mesh topology

From that point forward, the way test is completed with the tracert order. Following conditions after the way is broken when a tracert is performed. To discover which ways switch will pass. It very well may be found in Figure 8.

Testing with traceroute on full lattice geography with steering RIPv2. Ping from PC-1 to PC-8, the outcomes can be found in the Figure 9. Replay results show that the customer is now associated with PC-1. From that point forward, the way test is done with the tracert order. Here's the condition before the way is broken when a tracert is performed. To discover which ways switch will pass. Can be found in Figure 10. The implementation phase is the stage of applying the results of the analysis and research design that have been made before. The requirements needed for the system to run optimally are cisco packet tracert software. 
Table 1. Router configuration

\begin{tabular}{|c|c|c|c|c|c|c|c|c|c|}
\hline & Router 1 & & Router 2 & & Router 3 & & Router 4 & & Router 5 \\
\hline F0 & $192.168 .1 .1 / 24$ & F0 & $192.168 .1 .2 / 24$ & F0 & $192.168 .2 .2 / 24$ & F0 & $192.168 .3 .2 / 24$ & F0 & $192.168 .4 .2 / 24$ \\
\hline $\mathrm{F} 1$ & $192.168 .2 .1 / 24$ & $\mathrm{~F} 1$ & $192.168 .10 .1 / 24$ & $\mathrm{~F} 1$ & $192.168 .19 .1 / 24$ & $\mathrm{~F} 1$ & $192.168 .20 .2 / 24$ & $\mathrm{~F} 1$ & $192.168 .19 .2 / 24$ \\
\hline $\mathrm{F} 2$ & $192.168 .3 .1 / 24$ & $\mathrm{~F} 2$ & $\begin{array}{c}20.20 .20 .1 / 24 \\
P C=20.20 .20 .2 / 24\end{array}$ & $\mathrm{~F} 2$ & $192.168 .20 .1 / 24$ & $\mathrm{~F} 2$ & $192.168 .27 .1 / 24$ & $\mathrm{~F} 2$ & $192.168 .27 .2 / 24$ \\
\hline F3 & $192.168 .4 .1 / 24$ & F3 & $192.168 .12 .1 / 24$ & F3 & $192.168 .21 .1 / 24$ & F3 & $192.168 .28 .1 / 24$ & F3 & $192.168 .34 .1 / 24$ \\
\hline F4 & $192.168 .5 .1 / 24$ & F4 & $192.168 .13 .1 / 24$ & F4 & $192.168 .22 .1 / 24$ & F4 & $192.168 .29 .1 / 24$ & F4 & $192.168 .35 .1 / 24$ \\
\hline F5 & $192.168 .6 .1 / 24$ & F5 & $192.168 .14 .1 / 24$ & F5 & $192.168 .23 .1 / 24$ & F5 & $192.168 .30 .1 / 24$ & F5 & $192.168 .36 .1 / 24$ \\
\hline F6 & $192.168 .7 .1 / 24$ & F6 & $192.168 .15 .1 / 24$ & F6 & $192.168 .24 .1 / 24$ & F6 & $192.168 .15 .2 / 24$ & F6 & $192.168 .37 .1 / 24$ \\
\hline F7 & $192.168 .8 .1 / 24$ & F7 & $192.168 .16 .1 / 24$ & F7 & $192.168 .25 .1 / 24$ & F7 & $192.168 .31 .1 / 24$ & F7 & $192.168 .38 .1 / 24$ \\
\hline F8 & $192.168 .9 .1 / 24$ & F8 & $192.168 .17 .1 / 24$ & F8 & $192.168 .10 .2 / 24$ & F8 & $192.168 .32 .1 / 24$ & F8 & $\begin{array}{c}40.40 .40 .1 / 24 \\
\mathrm{PC}=40.40 .40 .2 / 24\end{array}$ \\
\hline F9 & $\begin{array}{c}10.10 .10 .1 / 24 \\
\mathrm{PC}=10.10 .10 .2 / 24\end{array}$ & F9 & $192.168 .18 .1 / 24$ & F9 & $\begin{array}{c}30.30 .30 .1 / 24 \\
\mathrm{PC}=30.30 .30 .2 / 24\end{array}$ & & & F9 & $192.168 .17 .2 / 24$ \\
\hline & Router 6 & & Router 7 & & Router 8 & & Router 9 & & Router 10 \\
\hline F0 & $192.168 .6 .2 / 24$ & F0 & $192.168 .5 .2 / 24$ & F0 & $192.168 .8 .2 / 24$ & F0 & $192.168 .7 .2 / 24$ & F0 & $192.168 .9 .2 / 24$ \\
\hline $\mathrm{F} 1$ & $192.168 .25 .2 / 24$ & $\mathrm{~F} 1$ & $192.168 .21 .2 / 24$ & $\mathrm{~F} 1$ & $192.168 .24 .2 / 24$ & $\mathrm{~F} 1$ & $192.168 .22 .2 / 24$ & $\mathrm{~F} 1$ & $192.168 .23 .2 / 24$ \\
\hline $\mathrm{F} 2$ & $192.168 .36 .2 / 24$ & $\mathrm{~F} 2$ & $192.168 .34 .2 / 24$ & $\mathrm{~F} 2$ & $192.168 .37 .2 / 24$ & $\mathrm{~F} 2$ & $192.168 .35 .2 / 24$ & $\mathrm{~F} 2$ & $192.168 .38 .2 / 24$ \\
\hline F3 & $192.168 .39 .1 / 24$ & F3 & $192.168 .42 .2 / 24$ & F3 & $192.168 .39 .2 / 24$ & $\mathrm{~F} 3$ & $192.168 .41 .2 / 24$ & F3 & $192.168 .40 .2 / 24$ \\
\hline $\mathrm{F} 4$ & $192.168 .40 .1 / 24$ & $\mathrm{~F} 4$ & $192.168 .43 .1 / 24$ & $\mathrm{~F} 4$ & $192.168 .46 .1 / 24$ & $\mathrm{~F} 4$ & $192.168 .48 .1 / 24$ & $\mathrm{~F} 4$ & $192.168 .48 .2 / 24$ \\
\hline F5 & $192.168 .41 .1 / 24$ & F5 & $192.168 .44 .1 / 24$ & F5 & $192.168 .47 .1 / 24$ & F5 & $192.168 .46 .2 / 24$ & F5 & $192.168 .47 .2 / 24$ \\
\hline F6 & $192.168 .42 .1 / 24$ & F6 & $192.168 .45 .1 / 24$ & F6 & $192.168 .45 .2 / 24$ & F6 & $192.168 .43 .2 / 24$ & F6 & $192.168 .30 .2 / 24$ \\
\hline F7 & $192.168 .28 .2 / 24$ & F7 & $192.168 .16 .2 / 24$ & F7 & $192.168 .14 .2 / 24$ & F7 & $192.168 .29 .2 / 24$ & F7 & $192.168 .44 .2 / 24$ \\
\hline F8 & $192.168 .12 .2 / 24$ & $\mathrm{~F} 8$ & $192.168 .32 .2 / 24$ & F8 & $192.168 .31 .2 / 24$ & F8 & $192.168 .13 .2 / 24$ & F8 & $192.168 .18 .2 / 24$ \\
\hline F9 & $\begin{array}{c}50.50 .50 .1 / 24 \\
\mathrm{PC}=50.50 .50 .2 / 24\end{array}$ & F9 & $\begin{array}{c}60.60 .60 .1 / 24 \\
\mathrm{PC}=60.60 .60 .2 / 24\end{array}$ & F9 & $\begin{array}{c}70.70 .70 .1 / 24 \\
\mathrm{PC}=70.70 .70 .2 / 24\end{array}$ & F9 & $\begin{array}{c}80.80 .80 .1 / 24 \\
\mathrm{PC}=80.80 .80 .2 / 24\end{array}$ & F9 & $\begin{array}{c}90.90 .90 .1 / 24 \mathrm{PC} \\
90.90 .90 .2 / 24\end{array}$ \\
\hline
\end{tabular}

Another sample
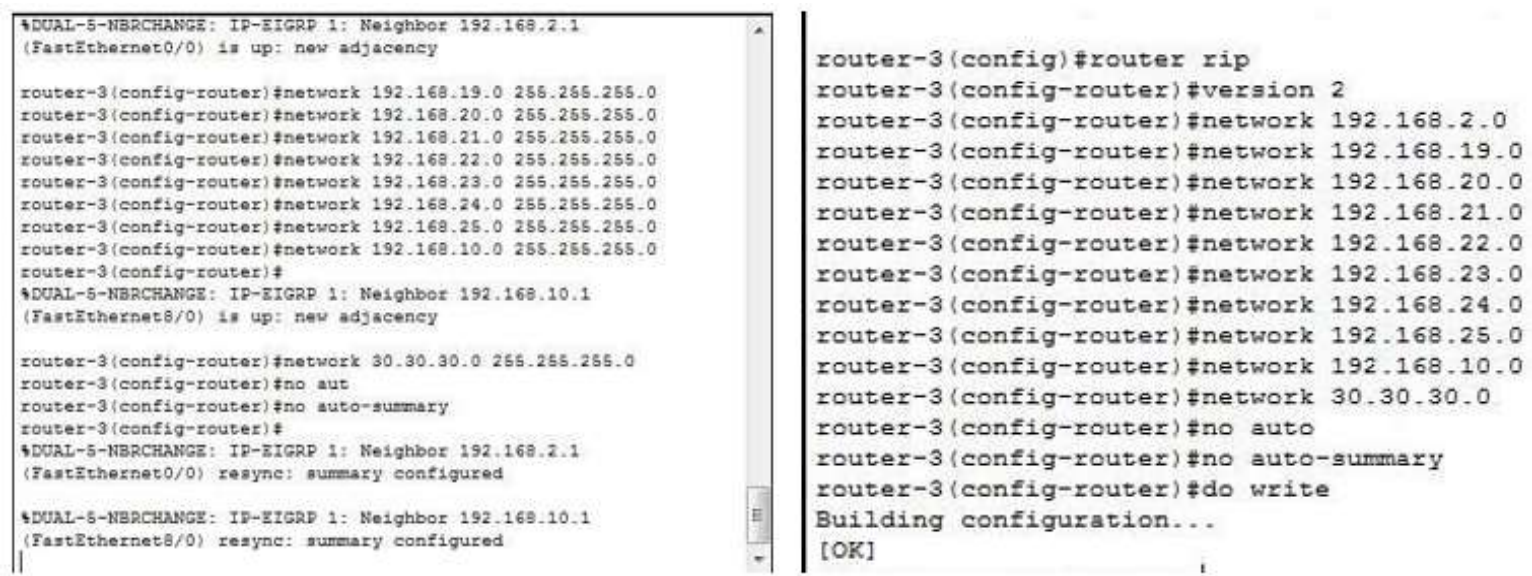

Figure 4. Sample configuration network and router on Route 3 using EIGRP and RIPv2

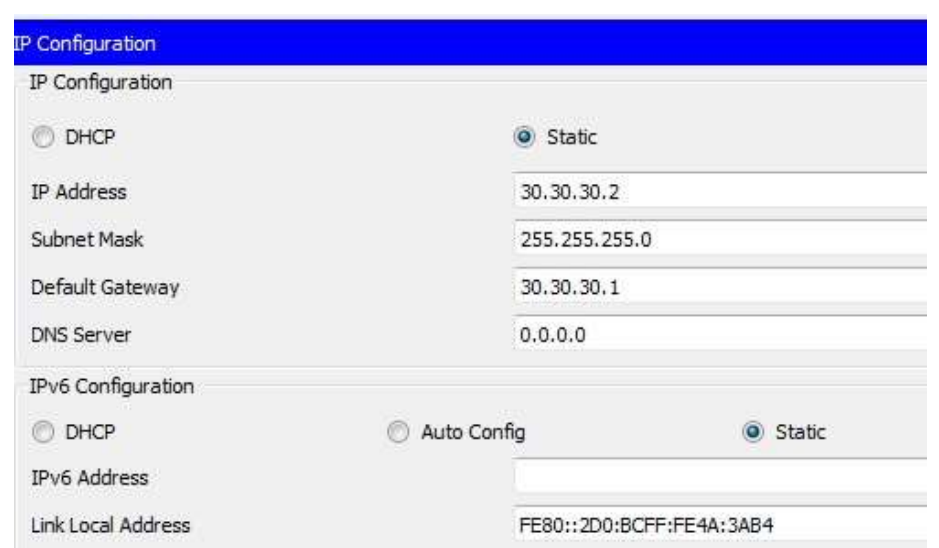

Figure 5. Sample configuration IP client 


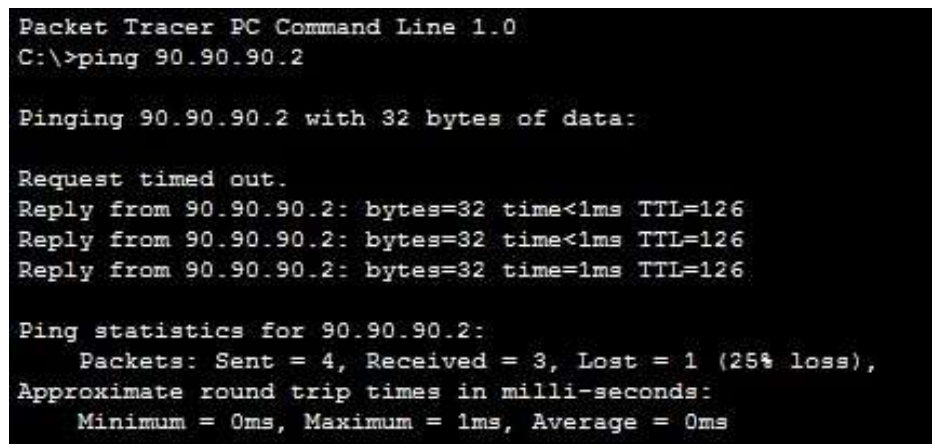

Figure 6. Sample test sending packet route 2 to route 10

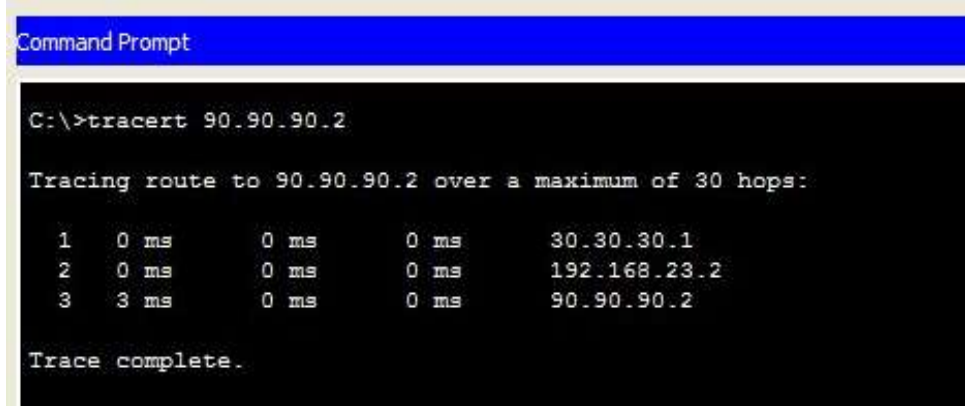

Figure 7. Sample result EIGRP routing on router 3 to router 10 before tracert

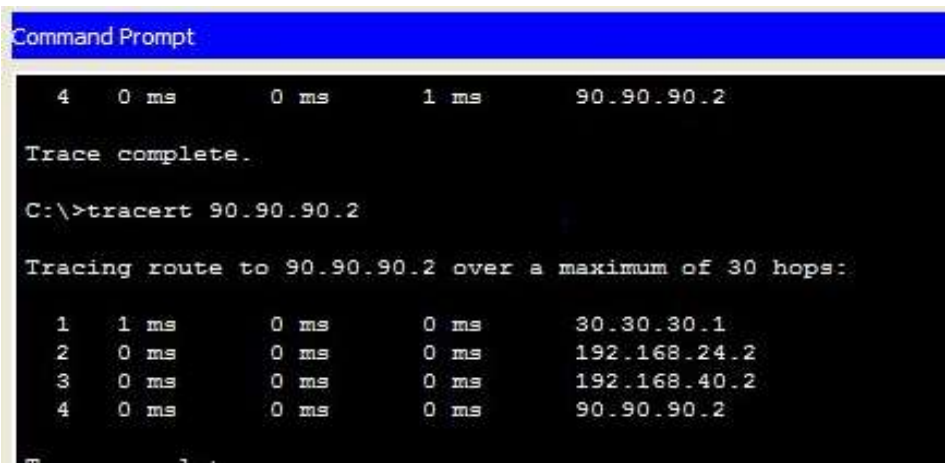

Figure 8. Sample result EIGRP routing on router 3 to router 10 after tracert

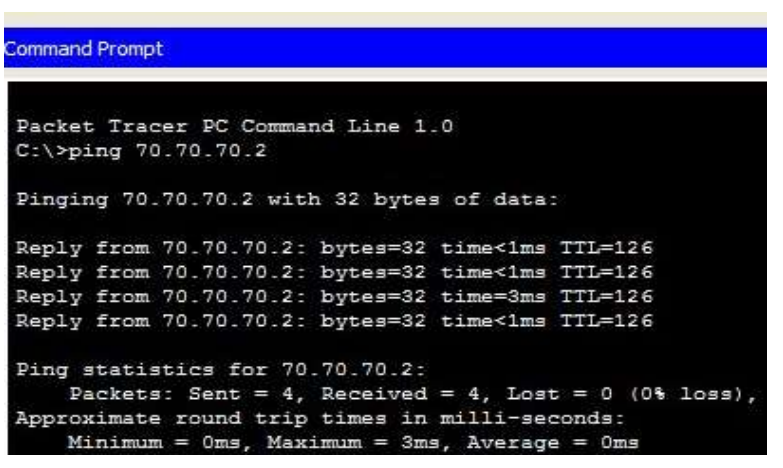

Figure 9. Sample result RIPv2 routing on router 1 to router 8 before tracert

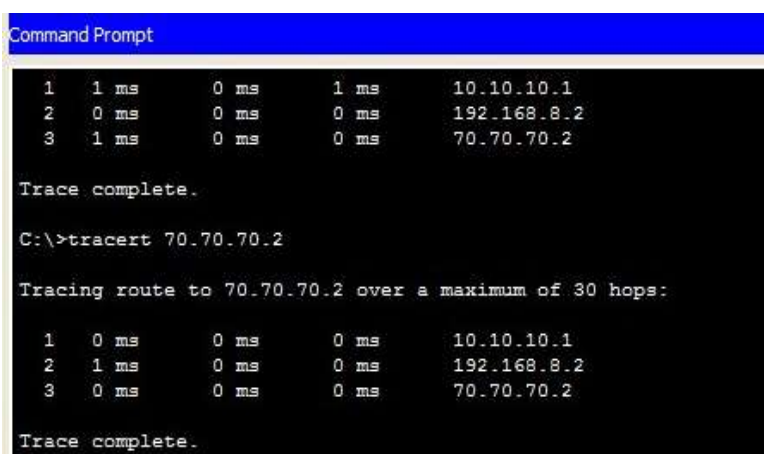

Figure 10. Sample result RIPv2 routing on router 1 to router 8 after tracert 


\subsection{Time testing}

Time testing is carried out on line termination after termination when sending packages. The following table results from the time tests conducted in Table 2 for fullmesh with EIGRP routing and Table 3 for fullmesh with RIPv2. Perform ping tests continuously then break up, a delay time will appear. The results of the experiment for routing EIGRP on full topology the mesh is shown in Table 2. The results of the experiments for EIGRP routing in full mesh topology are shown in Table 3.

\begin{tabular}{ccc}
\multicolumn{3}{c}{ Table 2. Fullmesh EIGRP } \\
\hline No & Experiment & Time \\
\hline 1 & PC $2 \rightarrow$ PC 3 & $0.01 \mathrm{~ms}$ \\
2 & PC $2 \rightarrow$ PC 7 & $0.02 \mathrm{~ms}$ \\
3 & PC 2 $\rightarrow$ PC 8 & $0.02 \mathrm{~ms}$ \\
4 & PC $2 \rightarrow$ PC 9 & $0.02 \mathrm{~ms}$ \\
5 & PC $2 \rightarrow$ PC 10 & $0.01 \mathrm{~ms}$ \\
\hline
\end{tabular}

Table 3. Fullfmesh RIPv2

\begin{tabular}{ccc}
\hline No & Experiment & Time \\
\hline 1 & PC $2 \rightarrow$ PC 9 & $0.15 \mathrm{~ms}$ \\
2 & PC $2 \rightarrow$ PC 10 & $0.19 \mathrm{~ms}$ \\
3 & PC $2 \rightarrow$ PC 7 & $0.07 \mathrm{~ms}$ \\
4 & PC 2 $\rightarrow$ PC 6 & $0.16 \mathrm{~ms}$ \\
5 & PC 2 $\rightarrow$ PC 8 & $0.17 \mathrm{~ms}$ \\
6 & PC 2 $\rightarrow$ PC 5 & $0.12 \mathrm{~ms}$ \\
7 & PC 2 $\rightarrow$ PC 3 & $0.11 \mathrm{~ms}$ \\
8 & PC 2 $\rightarrow$ PC 1 & $0.05 \mathrm{~ms}$ \\
\hline
\end{tabular}

Furthermore, time testing is carried out on the line termination after termination when sending the package. The following table results from half-timesh time testing with EIGRP routing and table. The time-testing test is performed on the termination of the lane after termination when sending the packet. The following Table 4 results from half-timesh time testing with RIPv2 and table routing. Doing a continuous pinging test then breaking up, a delay time will appear. Explanation of the termination process. Furthermore, time testing is carried out on the line termination after termination when sending the package. The following Table 5 results from halfmesh time testing with EIGRP routing.

Table 4. Half mesh RIPv2

\begin{tabular}{ccc}
\hline No & Experiment & Time \\
\hline 1 & PC $6 \rightarrow$ PC 9 & $0.17 \mathrm{~ms}$ \\
2 & PC $8 \rightarrow$ PC 1 & $0.06 \mathrm{~ms}$ \\
\hline
\end{tabular}

\begin{tabular}{ccc}
\multicolumn{3}{c}{ Table 5 . Half mesh EIGRP } \\
\hline No & Experiment & Time \\
\hline 1 & PC $1->$ PC 10 & $0.01 \mathrm{~ms}$ \\
2 & PC $2 \rightarrow$ PC 6 & $0.01 \mathrm{~ms}$ \\
\hline
\end{tabular}

\subsection{Analysis results}

The results of the analysis obtained from experiments conducted include:

- From EIGRP and RIPv2 routing experiments tested on 2 topologies there is a difference in the way messages are delivered to the package in each-respective router [25]. EIGRP routing characteristics that are classified as hybrid routing (distance vector and link state) which can make selections faster vector-based paths. EIGRP uses hello packet. Unlike the RIPv2 routing that has characteristics in distance vector routing. RIPv2 uses the request message for build relationships with neighboring routers.

- From the experiments conducted at the time of termination of the route/route in order to package which was tested on two topologies namely fullmesh and halfmesh. That package sent to its destination by testing carried out line termination, routing EIGRP has a better convergence time than routing RIPv2.

- Try using the ping command to send data packets by 32 bytes. EIGRP results are obtained in $1 \mathrm{~ms}$ and when on breaking up has time to replay with time 0.01 , and 0.02 which shows the speed of time is very good. As for RIPv2 when after being disconnected, the time needed for replays return range between 0.01-0.19 which shows the speed of time the good one.

- When routers do a routing table update on each topology, EIGRP only on routers that are directly affected from network changes. Whereas RIPv2 updates the table routing to all routers.

\section{CONCLUSION}

Based on research conducted, conclusions can be drawn including, from EIGRP and RIPv2 routing experiments it can be applied to topology fullmesh and halfmesh. The results of the discussions obtained indicate EIGRP has better convergence than RIPv2. Convergence is the time taken by the router to go through alternative path in order to reach the destination 


\section{REFERENCES}

[1] G. S. Permadi, K. Adi, and R. Gernowo, "Application Mail Tracking Using RSA Algorithm as Security Data and HOT-Fit a Model for Evaluation System," E3S Web of Conferences, vol. 31, 2018, pp. 1-6, Art. no. 11007, doi: $10.1051 / \mathrm{e} 3$ sconf/20183111007.

[2] D. R. Prehanto, A. D. Indriyanti, C. Mashuri, and G. S. Permadi, "Soil Moisture Predicti on using Fuzzy Time Series and Moisture sensor Technology on Shallot Farming," E3S Web of Conferences, vol. 125, 2019, pp. 1-5, Art. no. 23002, doi: 10.1051/e3sconf/201912523002.

[3] S. U. Masruroh, K. H. P. Widya, A. Fiade, and I. R. Julia, "Performance Evaluation DMVPN Using Routing Protocol RIP, OSPF, and EIGRP," 2018 6th International Conference on Cyber and IT Service Management, CITSM, 2019, pp. 1-6, doi: 10.1109/CITSM.2018.8674051.

[4] N. Alaparthi, S. R. Parvataneni, N. V. S. Kanderao, S. V. Jagtap, A. Donthu, and H. Korivi, "Performance comparison of CSMA, MACA, Generic MAC and Sensor MAC channel access protocols for ZigBee WSN with RIPv2 as Routing protocol," 2019 Innovations in Power and Advanced Computing Technologies, i-PACT 2019, 2019, doi: 10.1109/i-PACT44901.2019.8960033.

[5] A. Fiade, M. A. Agustian, and S. U. Masruroh, "Analysis of Failover Link System Performance in OSPF, EIGRP, RIPv2 Routing Protocol with BGP," 2019 Innovations in Power and Advanced Computing Technologies (i-PACT), vol. 1, 2019, pp. 1-5, doi: 10.1109/i-PACT44901.2019.8960033.

[6] H. K. Putri, L. V. Yovita, and R. M. Negara, "Performance analysis of csi: T routing in a delay tolerant networks," 2019 7th International Conference on Cyber and IT Service Management (CITSM), vol. 7, 2017, pp. 1-7, doi: 10.1109/CITSM47753.2019.8965373.

[7] C. G. Dumitrache, G. Predusca, L. D. Circiumarescu, N. Angelescu, and D. C. Puchianu, "Comparative study of RIP, OSPF and EIGRP protocols using Cisco Packet Tracer," 2017 4th International Conference on Electrical Engineering, Computer Science and Informatics (EECSI), 2017, pp. 1-6, doi: 10.1109/EECSI.2017.8239189.

[8] W. Myung, Z. Qi, and M. Cheng, "Performance Analysis of Routing Algorithms in Mesh Based Network on Chip using Booksim Simulator," 2017 5th International Symposium on Electrical and Electronics Engineering (ISEEE), 2019, pp. 1-6, doi: 10.1109/ISEEE.2017.8170694.

[9] S. Hu, Y. Jia, and C. She, "Performance analysis of VANET routing protocols and implementation of a VANET terminal," 2017 International Conference on Computer Technology, Electronics and Communication (ICCTEC), 2017, pp. 1248-1252, doi: 10.1109/ICCTEC.2017.00272.

[10] G. K. Dey, M. M. Ahmed, and K. T. Ahmmed, "Performance analysis and redistribution among RIPv2, EIGRP \& OSPF Routing Protocol," 2015 International Conference on Computer and Information Engineering (ICCIE), 2015, pp. 21-24, doi: 10.1109/CCIE.2015.7399308.

[11] S. U. Masruroh, A. Fiade, M. F. Iman, and Amelia, "Performance evaluation of routing protocol RIPv2, OSPF, EIGRP with BGP," 2017 International Conference on Innovative and Creative Information Technology (ICITech), 2018, pp. 1-7, doi: 10.1109/INNOCIT.2017.8319134.

[12] M. Kontšek, P. Segeč, M. Moravčík, and J. Uramova, "A Survey of the EIGRP Standard and Following Open-Source Implementations," 2018 16th International Conference on Emerging eLearning Technologies and Applications (ICETA), 2018, pp. 297-304, doi: 10.1109/ICETA.2018.8572146.

[13] K. Atefi, A. H. Shahin, S. Yahya, and A. Erfanian, "Performance evaluation of RIP and EIGRP Routing Protocols in IEEE 802.3u standard," 2016 3rd International Conference on Computer and Information Sciences (ICCOINS), 2016, pp. 209-214, doi: 10.1109/ICCOINS.2016.7783216.

[14] H. Hasan, J. Cosmas, Z. Zaharis, P. Lazaridis, and S. Khwandah, "Improvement of performance of EIGRP network by using a supervisory controller with smart congestion avoidance algorithm," 2016 International Conference on Telecommunications and Multimedia (TEMU), 2016, pp. 1-8, doi: 10.1109/TEMU.2016.7551925.

[15] M. Athira, L. Abrahami, and R. G. Sangeetha, "Study on network performance of interior gateway protocols-RIP, EIGRP and OSPF," 2017 International Conference on Nextgen Electronic Technologies: Silicon to Software (ICNETS2), 2017, pp. 244-248, doi: 10.1109/ICNETS2.2017.8067958.

[16] Z. Dawei, Y. Jing, C. Rui, Y. Jie, and H. Xinyu, "The Implementation of Routing Information Protocol Porting to the Switching System,” 2015 Seventh International Conference on Measuring Technology and Mechatronics Automation, 2015, pp. 1220-1223, doi: 10.1109/ICMTMA.2015.297.

[17] Naresh and A. Kumar, "Performance evaluation of UMTS under OSPF, EIGRP and IGRP," 2014 International Conference on Computing for Sustainable Global Development (INDIACom), 2014, pp. 934-938, doi: 10.1109/IndiaCom.2014.6828101.

[18] Meenakshi, A. Kaushik, and Satvika, "Performance comparison of routing protocols using OPNET UMTS model suite," 2014 International Conference on Signal Propagation and Computer Technology (ICSPCT 2014), 2014, pp. 668-672, doi: 10.1109/ICSPCT.2014.6884957.

[19] Nurhayati and R. F. Al Farizky, "Routing protocol RIPng, OSPFv3, and EIGRP on IPv6 for video streaming services," 2017 5th International Conference on Cyber and IT Service Management (CITSM), 2017, pp. 1-6, doi: 10.1109/CITSM.2017.8089250.

[20] D. X. Dzurovcak and S. Yang, "Performance Analysis of Routing Protocols in Delay Tolerant Networks," 2017 IEEE 14th International Conference on Mobile Ad Hoc and Sensor Systems (MASS), 2017, pp. 511-515, doi: 10.1109/MASS.2017.82.

[21] M. Ajdari, P. Park, J. Kim, D. Kwon, and J. Kim, "CIDR: A cost-effective in-line data reduction system for t erabit-per-second scale SSD arrays," 2019 IEEE International Symposium on High Performance Computer Architecture (HPCA), 2019, pp. 28-41, doi: 10.1109/HPCA.2019.00025. 
[22] R. Singh and S. Dewra, "Performance evaluation of star, tree \& mesh optical network topologies using optimized Raman-EDFA Hybrid Optical Amplifier," 2015 International Conference on Trends in Automation, Communications and Computing Technology (I-TACT-15), 2015, pp. 1-6, doi: 10.1109/ITACT.2015.7492667.

[23] M. N. Mohd Warip, I. Glesk, and I. Andonovic, "Power minimizing techniques for full mesh topology optical IP networks," 2011 16th European Conference on Networks and Optical Communications, 2011, pp. 129-132.

[24] O. Moriwaki, K. Noguchi, T. Sakamoto, and H. Takahashi, "Full-mesh wavelength channel assignments over interconnected star-shaped networks employing coprime-channel-cycle arrayed-waveguide gratings," IIEEE Photonics Technology Letters, vol. 22, no. 5, pp. 302-304, 2010, doi: 10.1109/LPT.2009.2039127.

[25] Meenakshi, A. Kaushik, and Satvika, "QoS parameter evaluation of UMTS under EIGRP, IGRP and RIP using OPNET," 2014 International Conference on Communication and Signal Processing, 2014, pp. 399-403, doi: 10.1109/ICCSP.2014.6949871.

\section{BIOGRAPHIES OF AUTHORS}

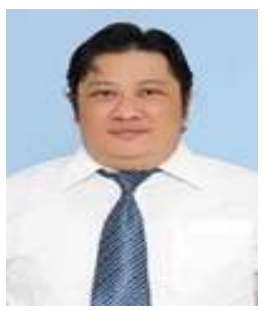

Dedy Rahman Prehanto received her S.Kom degree from the Information Systems Department, STIKOM, Surabaya, Indonesia, at 2005, and an M.Kom degree from the Masters in Information Systems, Postgraduate School, Diponegoro University, Semarang, Indonesia in 2012. He is currently completing a doctoral program in information systems, Diponegoro University. He is currently a lecturer and researcher at Department of Information Systems, State University of Surabaya, Indonesia. His current research interests include big data, expert systems, and iot

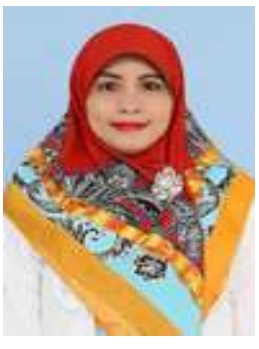

Aries Dwi Indriyanti received his S.Kom degree from the Information Systems Department, STIKOM, Surabaya, Indonesia, at 1998, and an M.Kom degree from the Masters in Information Systems, Postgraduate School, Diponegoro University, Semarang, Indonesia in 2009. She is currently completing a doctoral program in information systems, Diponegoro University. She is currently a lecturer and researcher at Department of Information Systems, State University of Surabaya, Indonesia. His current research interests include statistics, forecasting, supply chain and big data.

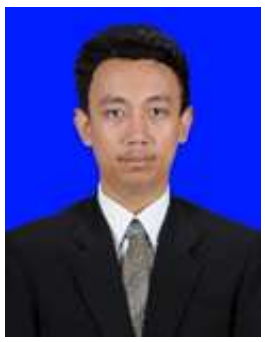

Ginanjar Setyo Permadi received her S.Kom degree majoring in information systems, STMIK AMIKOM, Yogyakarta, Indonesia, at 2015, and an M.Kom degree from the Masters in Information Systems, Postgraduate School, Diponegoro University, Semarang, Indonesia in 2017. He is currently a lecturer and researcher at Informatics management department, Hashim Ashari University, Jombang, Indonesia. His current research interests include big data, expert systems, data mining, data warehouse and iot 